Pacific Journal of Mathematics

A NOTE ON SECOND ORDER DIFFERENTIAL INEQUALITIES 


\title{
A NOTE ON SECOND ORDER DIFFERENTIAL INEQUALITIES AND FUNCTIONAL DIFFERENTIAL EQUATIONS
}

\author{
HUgo TeUfeL, JR.
}

\begin{abstract}
Criteria are established for the nonexistence of eventually positive solutions of a second order differential inequality. The oscillation of all solutions of large classes of functional differential equations follows as corollaries.
\end{abstract}

1. Introduction. Study of the behavior of solutions of equations like

$$
x^{\prime \prime}+F\left(t, x, x^{\prime}\right)=0,
$$

where $x F \geqq 0$, often entails study of the behavior of solutions of an inequality system like

$$
x^{\prime \prime}+H(t, x) \leqq 0, \quad x \geqq 0,
$$

where $x F \geqq x H \geqq 0$ and $H$ is selected for its tractability to analysis [6].

In this note it is shown that oscillation properties of large classes of equations

$$
x^{\prime \prime}+F(t, x(t), x(t-\tau(t)))=0
$$

can be established by use of inequalities like (1).

Thus, whenever feasible, inequalities like (1) should be primary objects of investigation.

2. Preliminaries. The inequality system discussed in this note is

$$
x^{\prime \prime}+a(t) N(x) \leqq 0, \quad x \geqq 0,
$$

where $a(t)$ is nonnegative and continuous on $[0, \infty)$, and $N(x)$ is positive on $(0, \infty)$ and continuous and nondecreasing on $[0, \infty)$. Note that $N(0)>0$ is permitted.

Three theorems are given on the nonexistence of eventually positive solutions of (3). Each theorem has a corollary concerning (2) where $F(t, u, v)$ is continuous on $[0, \infty) \times R_{2}$, and nondecreasing in $u$ and $v$ for $u v>0, \tau(t)$ is continuous on $[0, \infty)$, and

$$
\begin{gathered}
F(t, u, u) \geqq a(t) N(u), \quad u \geqq 0, \\
-F(t, u, u) \geqq a(t) N(-u), \quad u \leqq 0 .
\end{gathered}
$$


The term "solution" refers only to those solutions of equation (2) or inequality (3) which are defined and have a continuous second derivavative on some interval $[T, \infty), T \geqq 0$. Inequality (3) does not restrict a solution at those $t$-values where it is negative.

P. K. Wong [7] has discussed an inequality system like

$$
x^{\prime \prime}-a(t) N(x)>0, \quad x>0 .
$$

3. The results. Theorem 1 is suggested by an oscillation criterion for a special case of the equation (1) due to F. V. Atkinson [1].

THEOREM 1. Suppose

$$
\int^{\infty} t a(t) d t=\infty
$$

and, if $\alpha>0$,

$$
\int_{\alpha}^{\infty} N^{-1}(u) d u<\infty
$$

If $x(t)$ is a solution of (3) and $x\left(T_{0}\right)>0$ at some $T_{0}$ in $[0, \infty)$, then $x(t)$ has a zero in $\left(T_{0}, \infty\right)$.

Proof. Suppose $x(t)>0$ on $\left[T_{0}, \infty\right)$. Then $x(t)$ satisfies

$$
x^{\prime \prime}(t)+a(t) N(x(t)) \leqq 0 .
$$

If $x^{\prime}(t)$ has a zero in $\left[T_{0}, \infty\right)$ then, by the conditions on $a, N,(9)$ implies $x^{\prime \prime}(t) \leqq 0, x^{\prime \prime}(t) \neq 0$, on $\left[T_{0}, \infty\right)$. Thus, it is readily seen that $x(t)$ must have a zero in $\left[T_{0}, \infty\right)$.

Therefore, suppose $x^{\prime}(t)>0$ on $\left[T_{0}, \infty\right)$. An integration of (9) over $[s, t], T_{0} \leqq s<t$, gives, by neglect of positive $x^{\prime}(t)$,

$$
-x^{\prime}(s) \leqq-\int_{s}^{t} a(r) N(x(r)) d r \leqq-N(x(s)) \int_{s}^{t} a(r) d r .
$$

Division by $N(x(s))$ and an integration over $\left[T_{0}, t\right]$ gives

$$
-\int_{x\left(T_{0}\right)}^{x(t)} N^{-1}(u) d u \leqq-\int_{T_{0}}^{t}\left(s-T_{0}\right) a(s) d s .
$$

Clearly, if $t$ is sufficiently large (7) and (8) are contradicted. This proves the theorem.

Corollary 1. Given (2), suppose there exist functions $a, N$, which satisfy the conditions of the theorem and condition (4). Suppose $\tau=$ $\sup _{t} \tau(t)<\infty$. Then, each solution of (2) has a zero in each interval $\left[T_{0}, \infty\right)$ (is oscillatory). 
Proof. If $x(t)$ is a solution of (2), but is not oscillatory, then $x(t)>0$ on some interval $\left[T_{0}-\tau, \infty\right)$. And, necessarily, $x^{\prime}(t)>0$ on $\left[T_{c}, \infty\right)$, whereby, $x(t-\tau(t)) \geqq x(t-\tau)$ on $\left[T_{0}, \infty\right)$.

If $\tau \leqq 0, x(t-\tau) \geqq x(t)$ and $x(t)$ satisfies (9); thus, by Theorem 1 , there is a contradiction.

If $\tau>0$, then $x^{\prime \prime}(t) \leqq 0$ on $\left[T_{0}, \infty\right)$ implies

$$
x(t)-x(t-\tau) \leqq x^{\prime}\left(T_{0}\right) \tau, t \geqq T_{0}+\tau .
$$

Hence, there is a $\beta, 0<\beta<1$, such that $\beta x(t) \leqq x(t-\tau)$ and $x(t)$ is a solution of (3) on $\left[T_{0}+\tau, \infty\right)$ with $N(\beta x)$ in place of $N(x)$. The resulting contradiction proves the corollary.

Theorem 2 corresponds to the equation (1) where $F \equiv a(t)|x|^{r} \operatorname{sgn} x$, $0<\gamma<1$, whereas Theorem 1 holds for this $F$ with $\gamma>1$. The proof is based on a proof given by J. W. Heidel [2].

Notice that if on $\left[t_{0}, \infty\right) f(t)>0, f^{\prime}(t)>0$ continuous and nonincreasing, an integration shows that for each $\nu, 0<\nu<1$,

$$
f(t) \geqq \nu t f^{\prime}(t), t \geqq(1-\nu)^{-1} t_{0} \text {. }
$$

THEOREM 2. Suppose that in (3) $N(x)$ satisfies

$$
N(u v) \geqq \eta(u) N(v),
$$

for $u, v \geqq 0, u$ bounded, $v$ large, and for some continuous function $\eta(u)$. Suppose, also,

$$
\int^{\infty} N(t) a(t) d t=\infty,
$$

and the possibly improper integral,

$$
\int_{0}^{v} \eta^{-1}(u) d u
$$

exists for each finite $v$. If $x(t)$ is a solution of (3) and $x\left(T_{0}\right)>0$, then $x(t)$ must have a zero in $\left(T_{0}, \infty\right)$.

Proof. If $x(t)>0$ on $\left[T_{0}, \infty\right)$, then $x^{\prime}(t)>0$ and $x(t) \geqq 1 / 2\left(t x^{\prime}(t)\right)$ on $\left[T_{1}, \infty\right), T_{1}=2 T_{0}$. Therefore, $N(x(t)) \geqq \eta\left(1 / 2\left(x^{\prime}(t)\right)\right) N(t)$ and (9) leads to

$$
x^{\prime \prime}(t) \eta^{-1}\left(x^{\prime}(t)\right)+N(t) a(t) \leqq 0, \quad t \geqq T_{1} .
$$

An integration produces

$$
\int_{x^{\prime}\left(T_{1}\right)}^{x^{\prime}(t)} \eta^{-1}\left(\frac{1}{2} u\right) d u+\int_{T}^{t} N(s) a(s) d s \leqq 0
$$


Since $x^{\prime}(t)$ is nonincreasing this inequality with (13) contradicts the boundedness of (14). Hence, $x^{\prime}(t)$ must have a zero in $\left(T_{0}, \infty\right)$ and the theorem follows.

COROLLARY 2. If there exist functions $a(t), N(u)$, satisfying the conditions of the theorem and also satisfying (4), and if $\sup _{t} \tau(t)<$ $\infty$, then all solutions of (2) oscillate.

P. Waltman gave an example for an equation like (2) in which $t-\tau(t)$ increases more slowly than $t$, and the equation (2) has a nonoscillatory solution, while (2) with $\tau(t) \equiv 0$ has only oscillatory solutions. Corollary 3 slightly generalizes a sufficient condition for oscillation given in [5] for such cases. It holds for the linear equation

$$
x^{\prime \prime}(t)+a(t) x(t-\tau(t))=0 .
$$

TheoRem 3. In (3) let $a(t)$ and $N(x)$ have the properties mentioned, and in addition let

$$
\int^{\infty} a(t) d t=\infty
$$

Then; if $x(t)$ is a solution of $(3), x\left(T_{0}\right)>0$ implies $x(t)$ has a zero in $\left(T_{0}, \infty\right)$.

Proof. If the theorem is false $x(t)>x\left(T_{0}\right)$ on $\left(T_{0}, \infty\right)$ and $N(x(t))$ in (9) is greater than $N\left(x\left(T_{0}\right)\right)$. An integration produces a contradiction to $x^{\prime}(t)>0$ on $\left[T_{0}, \infty\right)$. This proves the theorem.

CoRollary 3. Given (3) suppose there exist funtions $a(t), N(u)$, satisfying (4). If a(t) satisfies (15) and $t-\tau(t) \rightarrow \infty$ as $t \rightarrow \infty$, then all solutions of (2) are oscillatory.

REMARK. The corollaries could have been given for equations more general than (2) where $F \equiv F\left(t, x\left(t-\tau_{1}(t)\right), \cdots, x\left(t-\tau_{n}(t)\right)\right)$ as in [3]. Also the $\tau(t)$ could have been expressed as explicitly dependent on $x(t)$ in certain ways. In [4] equations (2) which are nearly linear are discussed.

ACKNOWLEDGEMENT. The author thanks the referee for some improvements in the style of this note.

\section{REFERENCES}

1. F. V. Atkinson, On second order non-linear oscillation, Pacific J. Math., 5 (1955), 643-647.

2. J. W. Heidel, A short proof of Atkinson's oscillation theorem, SIAM Rev., 11 (1969), 
389-390.

3. H. Teufel, Jr., Second order nonlinear oscillation-deviating arguments, Monats. für Math., 75 (1971), 341-345.

4. - Second order almost linear functional differential equations-oscillation, Proc. Amer. Math. Soc., to appear.

5. P. Waltman, $A$ note on an oscillation criterion for an equation with a functional argument, Canad. Math. Bull., 11 (1968), 593-595.

6. J. S. W. Wong, On second order nonlinear oscillation, Funk. Ekvac., 11 (1969), 207-234.

7. P. K. Wong, Bounds for solutions to a classes of nonlinear second order differential equations, J. Differential Equations, 7 (1970), 139-146.

Received April 26, 1971.

Wichita State UNIVERSITY 



\section{PACIFIC JOURNAL OF MATHEMATICS}

\section{EDITORS}

\author{
H. SAMELSON \\ Stanford University \\ Stanford, California 94305

\section{R. HoвBY} \\ University of Washington \\ Seattle, Washington 98105
}

\section{J. DugundJI}

Department of Mathematics University of Southern California Los Angeles, California 90007

\author{
RichaRd ARENS \\ University of California \\ Los Angeles, California 90024
}

\section{ASSOCIATE EDITORS}
E. F. BECKENBACH
B. H. NEUMANN
F. WOLF
K. YoshidA

\section{SUPPORTING INSTITUTIONS}

\author{
UNIVERSITY OF BRITISH COLUMBIA \\ CALIFORNIA INSTITUTE OF TECHNOLOGY \\ UNIVERSITY OF CALIFORNIA \\ MONTANA STATE UNIVERSITY \\ UNIVERSITY OF NEVADA \\ NEW MEXICO STATE UNIVERSITY \\ OREGON STATE UNIVERSITY \\ UNIVERSITY OF OREGON \\ OSAKA UNIVERSITY
}

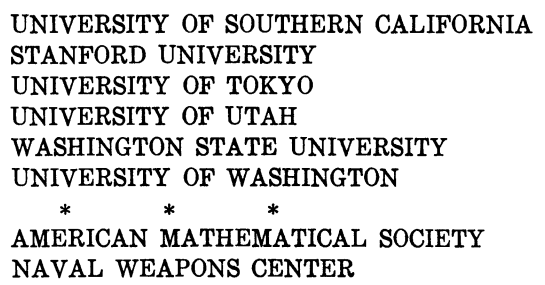

The Supporting Institutions listed above contribute to the cost of publication of this Journal, but they are not owners or publishers and have no responsibility for its content or policies.

Mathematical papers intended for publication in the Pacific Journal of Mathematics should be in typed form or offset-reproduced, (not dittoed), double spaced with large margins. Underline Greek letters in red, German in green, and script in blue. The first paragraph or two must be capable of being used separately as a synopsis of the entire paper. The editorial "we" must not be used in the synopsis, and items of the bibliography should not be cited there unless absolutely necessary, in which case they must be identified by author and Journal, rather than by item number. Manuscripts, in dup icate if possible, may be sent to any one of the four editors. Please classify according to the scheme of Math. Rev. Index to Vol. 39. All other communications to the editors should be addressed to the managing editor, Richard Arens, University of California, Los Angeles, California, 90024.

50 reprints are provided free for each article; additional copies may be obtained at cost in multiples of 50 .

The Pacific Journal of Mathematics is published monthly. Effective with Volume 16 the price per volume (3 numbers) is $\$ 8.00$; single issues, $\$ 3.00$. Special price for current issues to individual faculty members of supporting institutions and to individual members of the American Mathematical Society: $\$ 4.00$ per volume; single issues $\$ 1.50$. Back numbers are available.

Subscriptions, orders for back numbers, and changes of address should be sent to Pacific Journal of Mathematics, 103 Highland Boulevard, Berkeley, California, 94708.

PUBLISHED BY PACIFIC JOURNAL OF MATHEMATICS, A NON-PROFIT CORPORATION

Printed at Kokusai Bunken Insatsusha (International Academic Printing Co., Ltd.), 270, 3-chome Totsuka-cho, Shinjuku-ku, Tokyo 160, Japan. 


\section{Pacific Journal of Mathematics}

\section{Vol. 41, No. 2 December, 1972}

Tom M. (Mike) Apostol, Arithmetical properties of generalized Ramanujan sums .......................................... 281

David Lee Armacost and William Louis Armacost, On p-thetic groups ........ 295

Janet E. Mills, Regular semigroups which are extensions of groups .......... 303

Gregory Frank Bachelis, Homomorphisms of Banach algebras with minimal ideals ................................................ 307

John Allen Beachy, A generalization of injectivity .................. 313

David Geoffrey Cantor, On arithmetic properties of the Taylor series of rational functions. II.........................................

Václáv Chvátal and Frank Harary, Generalized Ramsey theory for graphs. III.

Small off-diagonal numbers .................................. 335

Frank Rimi DeMeyer, Irreducible characters and solvability of finite groups . . . . 347

Robert P. Dickinson, On right zero unions of commutative semigroups........ 355

John Dustin Donald, Non-openness and non-equidimensionality in algebraic

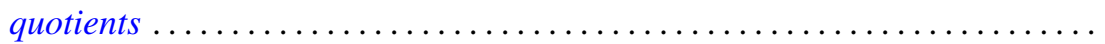

John D. Donaldson and Qazi Ibadur Rahman, Inequalities for polynomials with a prescribed zero ........................................ 375

Robert E. Hall, The translational hull of an $N$-semigroup ................ 379

John P. Holmes, Differentiable power-associative groupoids.............. 391

Steven Kenyon Ingram, Continuous dependence on parameters and boundary data for nonlinear two-point boundary value problems .

Robert Clarke James, Super-reflexive spaces with bases ..........

Gary Douglas Jones, The embedding of homeomorphisms of the plane in

continuous flows...............................

Mary Joel Jordan, Period $H$-semigroups and $t$-semisimple periodic

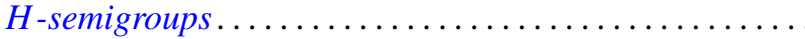

Ronald Allen Knight, Dynamical systems of characteristic 0

Kwangil Koh, On a representation of a strongly harmonic ring by sheaves...

Hui-Hsiung Kuo, Stochastic integrals in abstract Wiener space. ..

Thomas Graham McLaughlin, Supersimple sets and the problem of extending a

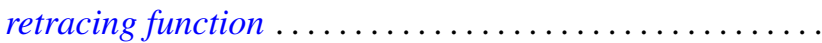

William Nathan, Open mappings on 2-manifolds .

M. J. O'Malley, Isomorphic power series rings

Sean B. O'Reilly, Completely adequate neighborhood systems and metrization

Qazi Ibadur Rahman, On the zeros of a polynomial and its derivative...

Russell Daniel Rupp, Jr., The Weierstrass excess function ..

Hugo Teufel, A note on second order differential inequalities and functional

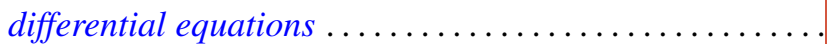

M. J. Wicks, A general solution of binary homogeneous equations over free 